\title{
Evaluation of the Bonapace Method: a specific educational intervention to reduce pain during childbirth
}

This article was published in the following Dove Press journal: Journal of Pain Research

3 September 2013

Number of times this article has been viewed

\begin{abstract}
Julie Bonapace'
Nils Chaillet ${ }^{2}$

Isabelle Gaumond ${ }^{3,4}$

Émilie Paul-Savoie ${ }^{5}$

Serge Marchand ${ }^{3,4}$
\end{abstract}

'Département des Sciences de l'Éducation, Université du Québec en Abitibi-

Témiscamingue, Rouyn-Noranda, Québec, ${ }^{2}$ Centre de Recherche de l'Hôpital SainteJustine, Université de Montréal, Montréal, Québec, ${ }^{3}$ Département de chirurgie, Faculté de Médecine et des Sciences de la Santé, Université de Sherbrooke, Sherbrooke, Québec, ${ }^{4}$ Département des Sciences de la Santé, Université du Québec en AbitibiTémiscamingue, Rouyn-Noranda, Québec, ${ }^{5}$ École des sciences infirmières, Faculté de médecine et des sciences de la santé, Université de Sherbrooke, Sherbrooke, Québec, Canada

\section{Video abstract}

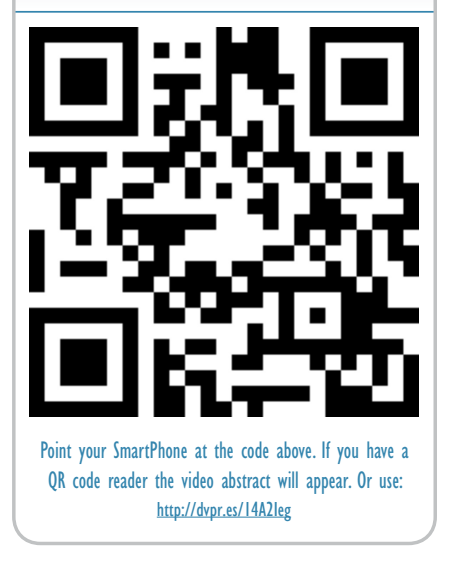

Correspondence: Serge Marchand Université de Sherbrooke, Faculté de Médecine et des Sciences de la Santé, Axe Douleur CRCELB; 300I, I2e Avenue Nord, Sherbrooke, Canada JIH $5 \mathrm{~N} 4$

Tel + I 819346 I I I0 ext 15889

$\mathrm{Fax}+\mathrm{I} 8195645424$

Email serge.marchand@usherbrooke.ca
Objective: As pain during childbirth is very intense, several educational programs exist to help women prepare for the event. This study evaluates the efficacy of a specific pain management program, the Bonapace Method (BM), to reduce the perception of pain during childbirth. The BM involves the father, or a significant partner, in the use of several pain control techniques based on three neurophysiological pain modulation models: (1) controlling the central nervous system through breathing, relaxation, and cognitive structuring; (2) using non-painful stimuli as described in the Gate Control Theory; and (3) recruiting descending inhibition by hyperstimulation of acupressure trigger points.

Methods: A multicenter case control study in Quebec on pain perception during labor and delivery compared traditional childbirth training programs (TCTPs) and the BM. Visual analog scales were used to measure pain perception during labor. In all, 25 women (TCTP: $n=12$; BM: $n=13$ ) successfully reported their perceptions of pain intensity and unpleasantness every 15 minutes.

Results: A positive correlation between the progression of labor and pain was found (pain intensity: $P<0.01$; pain unpleasantness: $P<0.01$ ). When compared to TCTP, the BM showed an overall significant lower pain perception for both intensity $(45 \% ; P<0.01)$ and unpleasantness $(46 \% ; P<0.01)$.

Conclusion: These significant differences in pain perception between TCTP and the BM suggest that the emphasis on pain modulation models and techniques during labor combined with the active participation of a partner in BM are important variables to be added to the traditional childbirth training programs for childbirth pain management.

Keywords: labor pain, yoga, perinatal care, DNIC, gate control theory, cognitive structuring, massage, father

\section{Introduction}

Pain is defined as an unpleasant sensory and emotional experience associated with actual or potential tissue damage. ${ }^{1}$ It consists of at least two components that are supported by independent neurophysiological pathways: the sensory-discriminative component (intensity) and the motivational-affective component (unpleasantness), which can be selectively modulated. Although the intensity of pain that women feel in childbirth is not usually associated with tissue damage, studies have ranked it as among the most severe forms of pain ever recorded using the McGill Pain Questionnaire or visual analog scales (VAS). ${ }^{2,3}$ The physiological and psychological effects of pain during labor and delivery are numerous and hardly trivial. ${ }^{4,5}$ Although new pharmacological procedures to relieve childbirth pain have proven effective in reducing pain, ${ }^{6,7}$ they are frequently associated with a higher incidence of dystocia, instrumental 
deliveries, ${ }^{8,9}$ and complications. ${ }^{10}$ For example, women who use epidurals are more likely to need their labor contractions stimulated, to have a longer second stage of labor, the risk of instrumental delivery is increased (this is not associated with fetal distress) whereas the risk of caesarean section for fetal distress is increased. ${ }^{11}$

Traditional childbirth training programs (TCTPs) aimed at preparing parents for childbirth are widely developed in Western countries. However, the true effects of such training on the perception of pain are still uncertain, ${ }^{12}$ or controversial: some studies have found that training has no demonstrable effect on pain itself, but simply improves the reaction to pain. ${ }^{13,14}$ Others have found that women with adequate preparation experience from zero to $30 \%$ less pain during labor and delivery than women without preparation. ${ }^{2,15-18}$

As we previously found for chronic pain measurement, ${ }^{19}$ the primary explanation for this discrepancy regarding the perception of labor pain may be due to inadequate measurement methods, such as: (1) lack of sensitivity in pain measurement, ${ }^{13}$ (2) inadequate measurement of the components of pain, ${ }^{14}(3)$ measurement relying on the memory of pain, ${ }^{13,20}$ and (4) not accounting for pain modulation over time and context. ${ }^{2,17,20}$

Because of potential side effects and complications of the epidural procedure and the limited effect of traditional childbirth programs in reducing labor pain, optimal and noninvasive pain relief approaches are needed. The Bonapace Method (BM) proposes to involve the father, or a significant partner, in reducing labor pain by practicing pain modulation techniques based on three neurophysiological endogenous pain modulation models ${ }^{21}$ (Figure 1 and Table 1). First, the proposed method uses control of the central nervous system (CNSC) through breathing, relaxation, and cognitive structuring. Slow, deep breathing is often part of techniques frequently used to relieve pain, such as relaxation. ${ }^{22,27}$ Indeed, a recent study supports the use of slow breathing, by showing a reduction of experimental heat through the manipulation of breathing. ${ }^{23}$ Another pain modulation technique used in this method is non-painful stimulation, such as light massage of the back, between labor contractions. The analgesia created by light massage is based on the Gate Control Theory proposed by Melzack and Wall, ${ }^{24}$ where stimulation of nonnociceptive $A \beta$ afferent fibers inhibit the nociceptive signal transmitted by $\mathrm{A} \delta$ and $\mathrm{C}$ fibers. Indeed, some studies have shown that one could obtain a reduction of pain through massage and ambulation. ${ }^{25-28}$ Finally, the BM uses analgesic hyperstimulation during contractions. Fathers or partners are asked to create a second pain in acupressure trigger points

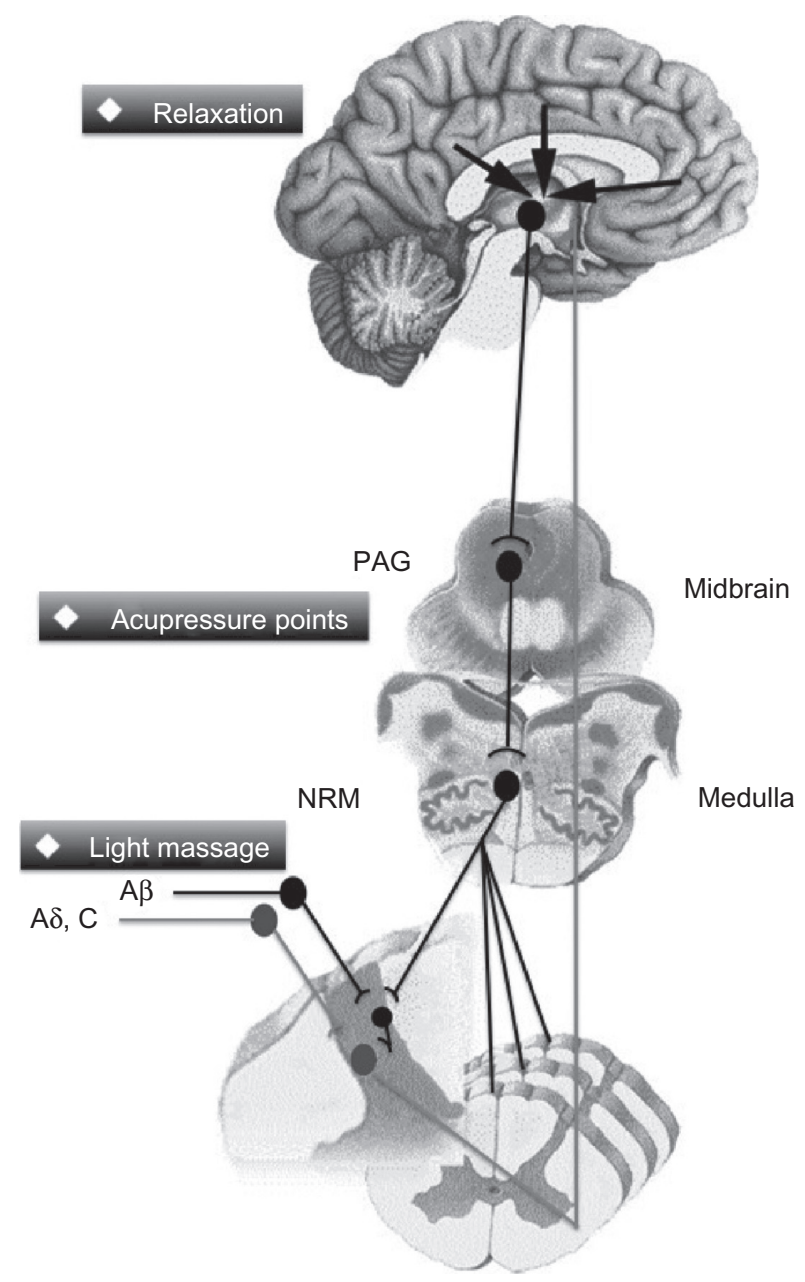

Figure I The different levels of pain modulation mechanisms used by the Bonapace Method.

Notes: Multiple brain regions (arrows) including the prefrontal and cingulate cortex are triggering descending inhibition from the NRM and PAG.

Abbreviations: NRM, nucleus raphe magnus; PAG, periaqueductal gray matter.

during contractions at all phases of labor and delivery. This type of stimulation seems to act by descending inhibitory projections that are coordinated in the rostroventral medulla and make up part of the spinal-bulbo-spinal diffuse noxious inhibitory control (DNIC) pathway. ${ }^{29,30}$ DNIC is a plausible mechanism by which acupressure to acupuncture ${ }^{27,31}$ points produces analgesia. ${ }^{32,33,34,35}$ From our perspective, a method combining these three neurophysiological endogenous pain modulation systems should demonstrate good efficacy in reducing both components of childbirth pain.

The aims of this multicenter case control study were: (1) to compare the effects on pain perception during labor and delivery between the BM, which specifically addresses pain modulation techniques, and TCTPs; (2) to better understand the relation between the progression of labor and pain, using validated measurement methods; and (3) to determine the potential for conducting a robust randomized controlled trial. 
Table I Bonapace Method mechanisms and techniques

\begin{tabular}{|c|c|c|c|c|}
\hline Theoretical model & Type of stimulation & Activated mechanism & Effects & Techniques \\
\hline $\begin{array}{l}\text { Gate control } \\
\text { theory }\end{array}$ & $\begin{array}{l}\text { Non-painful stimulation } \\
\text { of the pain site }\end{array}$ & $\begin{array}{l}\text { Fibers which do not transmit pain } \\
\text { messages are activated during } \\
\text { non-painful stimulation and block } \\
\text { part of those that transmit pain }\end{array}$ & $\begin{array}{l}\text { Acts only on the stimulated area. } \\
\text { Modulates the sensory- } \\
\text { discriminative component } \\
\text { of pain (intensity) }\end{array}$ & $\begin{array}{l}\text { - Light massage of back, } \\
\text { hips, and sacrum } \\
\text { - Positions/ambulation } \\
\text { - Yoga }\end{array}$ \\
\hline $\begin{array}{l}\text { Diffuse noxious } \\
\text { inhibitory control }\end{array}$ & $\begin{array}{l}\text { Painful stimulation of } \\
\text { any site of the body }\end{array}$ & $\begin{array}{l}\text { Painful stimulation which } \\
\text { reduces pain everywhere. } \\
\text { This allows the brain to address } \\
\text { the second source of pain }\end{array}$ & $\begin{array}{l}\text { Acts on all painful areas of } \\
\text { the body. Modulates the sensory- } \\
\text { discriminative component } \\
\text { of pain (intensity) }\end{array}$ & $\begin{array}{l}\text { - Painful massage } \\
\text { - Acupressure in B31-34, } \\
\text { GB30, LI4, L3 }\end{array}$ \\
\hline $\begin{array}{l}\text { Control of the higher } \\
\text { centers of the central } \\
\text { nervous system }\end{array}$ & $\begin{array}{l}\text { Activated by thought } \\
\text { and mental processes } \\
\text { (attention deviation) }\end{array}$ & $\begin{array}{l}\text { The brain modulates the } \\
\text { potentially painful stimulations } \\
\text { by conditioning the areas which } \\
\text { are responsible for memory, } \\
\text { emotions, and reaction to pain }\end{array}$ & $\begin{array}{l}\text { Acts on all painful areas } \\
\text { of the body. Modulates } \\
\text { the motivational-affective } \\
\text { component of pain } \\
\text { (unpleasantness) }\end{array}$ & $\begin{array}{l}\text { - Continuous support } \\
\text { - Relaxation/breathing } \\
\text { - Mental imagery } \\
\text { - Placebo } \\
\text { - Yoga }\end{array}$ \\
\hline
\end{tabular}

\section{Methods}

\section{Subjects}

Subjects for this study were recruited among patients of five medical clinics, affiliated with general hospitals, where no midwifery continuity of care programs were available, in the province of Quebec between 1995 and 1998. Subjects were informed of the nature of the study, which sought to better understand the perception of pain during childbirth, during their routine visit to the doctor, by a nurse or a research agent guided by a written protocol. Nothing was mentioned in relation to the correlation between the type of training and the perception of pain. All participating subjects were instructed on how to measure pain during labor and delivery using VAS. Each participant signed a consent form and received a pain management questionnaire to be completed during childbirth. After giving birth, they completed the demographic section of the questionnaire (age, parity, finances, education, onset of labor, and childbirth training). In accordance with the Université du Québec en Abitibi-Témiscamingue Human Subjects Ethics Committee, each subject was informed of her right to withdraw from the experiment at any time without prejudice. In consideration of the ethical problem involved in randomly imposing one type of treatment over another, the complexity involved in recruiting subjects for this study, and the need to determine the potential for a large, randomized controlled trial, we allowed subjects to assign themselves, during pregnancy, to the training program that best reflected their preferences: TCTP or the BM. All training programs were available at local community facilities, free of charge.

\section{Treatment}

The TCTP group consisted of women who had voluntarily chosen to follow that program with their partner. Training was started at approximately the $23 \mathrm{rd}$ week of pregnancy, and lasted a total of 8 hours over a 4-week period. The teaching curriculum of the TCTP was mostly based on a theoretical understanding of: (1) anatomy and physiology of childbirth; (2) physical well-being (exercises); (3) stages of labor and delivery; (4) variations in labor and birth; (5) pharmacological analgesia; and (6) caring for the newborn baby. Relaxation, visualization techniques, massages, and positions during labor were not taught in the TCTP. Only breathing techniques were practiced.

The BM group consisted of women who had voluntarily chosen to follow the specific pain management program with their partners. The curriculum of the BM incorporated the understanding of pain modulation mechanisms ${ }^{21,36}$ and the teaching of practical techniques related to those mechanisms. They included: (1) CNSC through breathing, relaxation, and cognitive structuring (origin of labor pain and endogenous pain modulating mechanisms); (2) non-painful stimuli, such as ambulation and light massage of the back by the partner between labor contractions, which activates non-nociceptive fibers and produces pain inhibition, as described in the Gate Control Theory; ${ }^{24}$ and (3) DNIC analgesic hyperstimulation, by the partner during contractions, using deep painful massage of acupuncture trigger points in the lower back (namely, Shanglia BL 31, Cilia BL 32, Zhongliao BL 33 and Xialiao BL 34), alternating with trigger points in the hand (Hegu LI 4), the foot (Taichong L 3), and on the buttocks (Huantiao GB 30). Partners were taught to use whichever mechanisms suited them best during childbirth. The training program lasted eight hours over a four-week period. The women were approximately in their 30th week of pregnancy, and the entire program was dedicated to pain management and partner participation. 


\section{Procedure}

Upon arrival at the hospital, each subject measured perceived pain intensity, and pain unpleasantness every 15 minutes immediately after a contraction, and at all phases of true labor and delivery. True labor was determined by contractions of increasing intensity, frequency, and length. ${ }^{37}$ Measurements were recorded using two separate VAS, which had been found valid for non-pharmacological analgesia measurement $^{19}$ and for the measurement of labor pain. ${ }^{2,3,38}$ The proposed methodology avoided the problems associated with pain measurements mentioned earlier. The pain VAS consisted of visual analog scales with verbal and numerical descriptors, whose end-points were designated as "no pain" and "the most intense imaginable", for pain intensity, and "not unpleasant at all" and "the most unpleasant imaginable", for pain unpleasantness. Cervical dilatation and medication were also recorded. Questionnaires were returned to hospital staff, then to research agents within days of the birth. Once the study was completed, data from subjects were grouped according to the training information they gave on their pain questionnaires.

In total, 39 women participated in this study. The TCTP group consisted of 19 women (ten multiparous and nine nulliparous); the BM group, 20 women (eight multiparous and twelve nulliparous). The criterion for determining parity was the number of times a woman had given birth to a foetus with a gestational age of 24 weeks or more, regardless of whether the child was born alive or was stillborn (none = nulliparous; once or more $=$ multiparous). All data collected after the use of pharmacotherapy (epidural or sedatives) was eliminated. A total of 25 women (twelve of the TCTP group: eight multiparous and four nulliparous, and 13 of the BM group: seven multiparous and six nulliparous) met the following criteria (which were specified before the beginning of the study): (1) they were in active labor; and (2) had registered data for at least two of the four stages of labor and delivery. In total, 14 subjects were eliminated: two subjects for using sedatives (TCTP: one nulliparous; BM: one nulliparous), six subjects for reverting to an epidural (TCTP: three nulliparous; BM: three nulliparous), and six subjects for having stopped entering data (TCTP: two multiparous and one nulliparous; BM: one multiparous and two nulliparous). Subject age ranged between 19 and 40 (TCTP mean: 26 years; BM mean: 27 years), all had at least twelve years of education (TCTP mean: 14 years; BM mean: 16 years), each had a comparable average annual income per family, and comparable spontaneous onset of labor (TCTP: 75\%; BM: 69.2\%). No significant difference was found between the TCTP and BM groups for these variables (Table 2).

\section{Statistical analysis}

The first analysis (all participants, regardless of the method or the parity; $n=25$ ) was made using pain ratings for the last six hours preceding delivery. A regression analysis compared the progression of pain with the progression of labor. The second series of analyses (all participants) separated labor and delivery in four phases:3,39 (1) early (one contraction every 5-20 minutes, cervical dilatation $0-4 \mathrm{~cm}$ at $<0.5 \mathrm{~cm} / \mathrm{hr}$ ); (2) active (one contraction every 2-4 minutes, cervical dilatation $4-8 \mathrm{~cm}$ at $>0.5 \mathrm{~cm} / \mathrm{hr}$ ); (3) transition (one contraction every 1-2 minutes, cervical dilatation $8-10 \mathrm{~cm}$ at $>1.5 \mathrm{~cm} / \mathrm{hr}$ ); and (4) pushing (one contraction every $2-3$ minutes, each lasting about $50-70$ seconds, combined with effort). The number of evaluations per subject varied between 3 and 34, depending on the moment of arrival at the obstetrical unit, and on the length of labor (mean: 16, SD: 9.06). The main effects analyzed were group (BM versus TCTP) and the interaction between group and parity. Post-hoc analyses were made using planned contrasts. A probability of less than $5 \%$ was considered significant. Statistical analyses were performed using SuperANOVA (Abacus Concepts, Berkeley, CA, USA), a general linear modeling program, and StatView (SAS Institute, Cary, NC, USA). Missing values (twelve out of 100 values), for subjects

Table 2 Demographic characteristics

\begin{tabular}{|c|c|c|c|c|c|}
\hline \multirow[t]{2}{*}{$\begin{array}{l}\text { Demographic } \\
\text { characteristics }\end{array}$} & \multicolumn{2}{|c|}{$\begin{array}{l}\text { Experimental } \\
\text { group }(n=13)\end{array}$} & \multicolumn{2}{|c|}{$\begin{array}{l}\text { Control } \\
\text { group }(n=12)\end{array}$} & \multirow[t]{2}{*}{$\chi^{2}$} \\
\hline & Number & $\%$ & Number & $\%$ & \\
\hline \multicolumn{6}{|l|}{ Maternal age (year) } \\
\hline $19-25$ & 6 & 46.1 & 6 & 50.0 & 0.62 \\
\hline $26-40$ & 7 & 53.9 & 6 & 50.0 & \\
\hline \multicolumn{6}{|l|}{ Education level } \\
\hline$\leq 12$ years & 3 & 23.1 & 3 & 25.0 & 0.11 \\
\hline$>12$ years & 10 & 76.9 & 9 & 75.0 & \\
\hline \multicolumn{6}{|l|}{ Income (CA\$) } \\
\hline $10,000-25,000$ & 2 & 15.3 & 4 & 33.3 & 0.44 \\
\hline $25,00 \mathrm{I}-40,000$ & 6 & 46.2 & 3 & 25.0 & \\
\hline $40,00 \mathrm{I}-50,000+$ & 5 & 38.5 & 5 & $4 I .7$ & \\
\hline \multicolumn{6}{|l|}{ Hospital } \\
\hline CHRN & 7 & 53.8 & 5 & $4 I .7$ & 0.53 \\
\hline HDA & 2 & 15.4 & 3 & 25.0 & \\
\hline $\mathrm{HM}$ & 4 & 30.8 & 2 & 16.7 & \\
\hline HPLG & 0 & 0 & I & 8.3 & \\
\hline CHRTR & 0 & 0 & I & 8.3 & \\
\hline Spontaneous labor & 9 & 69.2 & 9 & 75 & 0.75 \\
\hline
\end{tabular}

Abbreviations: CHRN, Centre Hospitalier de Rouyn-Noranda; HDA, Hôtel Dieu d'Amos; HM, Hôpital de Maria; HPLG, Hôpital Pierre-Le Gardeur; CHRTV, Centre Hospitalier Régional de Trois-Rivières. 
having completed two or more of the four stages of labor, were obtained by adding the mean value of the subject's total values to the mean value of their group's moment, minus the mean total value of their group. The statistical degrees of freedom were adjusted accordingly.

Independent sample $t$-tests and chi-squared or Fisher's exact tests were applied to determine if there were differences in demographic variables between experimental and control groups.

\section{Results}

\section{Increase in pain as a function of the progression of labor}

A positive correlation between pain and the progression of labor was found for both the TCTP and BM groups (pain intensity: $R=0.33, F=12.96, P=0.0005$; pain unpleasantness: $R=0.24, F=6.58, P=0.01)$. Pain intensity and unpleasantness significantly increased between the early and active phases and between the active and transition phases, as shown in Figure $2(F[3.72]=23.957, P=0.0001$, and $F[3.72]=26.892, P=0.0001$, respectively).

\section{Effect of the methods on pain}

Overall, VAS pain scores revealed that there was a significant difference in pain perception between the BM and TCTP groups (Table 3). More specifically, the BM group perceived an average of $44.6 \%$ less pain intensity $(F[1.25]=22.00, P=0.0001)$ and $46.5 \%$ less pain unpleasantness $(F[1.25]=11.26$, $P=0.003$ ), in comparison to the TCTP group (pain intensity: $\mathrm{BM}=44.14 \pm 16.08$ versus TCTP $=79.13 \pm 25.81$; and pain unpleasantness: $\mathrm{BM}=39.82 \pm 17.04$ versus $\mathrm{TCTP}=74.42 \pm 41.70$ ). This difference was significant regard-

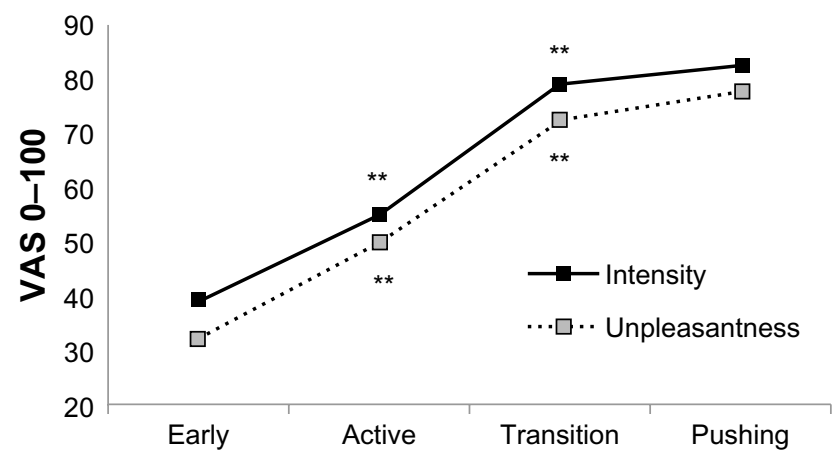

Figure 2 VAS pain scores during phases of labor.

Notes: A significant increase in pain intensity (solid line) and pain unpleasantness (broken line) between the different periods of labor is observed. As often reported by parturients, pain ceases to increase significantly between the transition and pushing phases; $* * P<0.01$.

Abbreviation: VAS, visual analog scale. less of parity, for pain intensity (nulliparous: $F[1.10]=13.74$, $P=0.0011$; multiparous: $F[1.15]=8.269, P=0.0083)$. For pain unpleasantness, however, this difference was found for nulliparous women only (nulliparous: $F[1.10]=10.74$, $P=0.0032$; multiparous: $F[1.15]=1.634, P=0.2134$ ) (Table 3 and Figure 3). A significant difference was also found between both programs for pain intensity during all four periods of labor, and for the active, transition, and pushing periods for pain unpleasantness (Table 4 and Figure 4). No difference was found for the use of pharmacological methods (sedatives and epidurals: $\mathrm{TCTP}=4 / 39 ; \mathrm{BM}=4 / 39$ ).

\section{Discussion}

To our knowledge, no other study has documented with precision the progression of pain during all phases of labor and delivery using a validated pain-measuring tool. Our findings show that pain increases in a predictable manner with the progression of labor. Although the perception of pain varied greatly from one woman to another, the mean pain ratings of both groups revealed a steady and significant increase in pain intensity and unpleasantness with the dilation of the cervix, consistent with descriptions in obstetrical books ${ }^{39}$ and previous research. ${ }^{40} \mathrm{~A}$ regression analysis confirmed these findings.

Regarding the overall effect of the BM, the present findings demonstrate an important reduction in pain intensity and unpleasantness perception with the BM, compared to TCTP. The significant effect of the BM on the reduction of pain intensity for both nulliparous and multiparous women indicates that an effective pain management program can be useful in increasing coping attitudes, regardless of previous experience with birth (Figure 3). Differences are particularly important during the longest and the most difficult phases of parturition (active, transition, and pushing phases) (Figure 4). The lack of difference for pain unpleasantness between multiparous women may be explained by "experience". It is well known that one of the main concerns of nulliparous women is fear of the unknown (childbirth), which in turn increases the subjective dimension of pain. Multiparous women, because of their previous experience with labor pain, have a better understanding of what to expect during childbirth. It is this reduction of fear and anxiety that may be responsible for less pain unpleasantness during parturition. ${ }^{2}$

Consistent with studies on massage, ${ }^{26}$ ambulation, ${ }^{28}$ support, ${ }^{41}$ acupressure ${ }^{35}$ and yoga ${ }^{42}$ our results show that these methods help cope with pain. Yoga, acting on both the body (pain intensity) and the mind (pain unpleasantness), has proven to be effective in reducing pain perception ${ }^{42}$ 
Table 3 Mean pain perception, standard deviation, and differences in pain reduction between the methods, according to parity

\begin{tabular}{|c|c|c|c|c|c|c|}
\hline & \multicolumn{3}{|c|}{ Pain intensity } & \multicolumn{3}{|c|}{ Pain unpleasantness } \\
\hline & $\begin{array}{l}\text { TCTP } \\
(n=I 2)\end{array}$ & $\begin{array}{l}\text { BM } \\
(n=13)\end{array}$ & Difference & $\begin{array}{l}\text { TCTP } \\
(n=I 2)\end{array}$ & $\begin{array}{l}B M \\
(n=13)\end{array}$ & Difference \\
\hline \multirow[t]{2}{*}{ Overall VAS scores } & 79.73 & 44.14 & $44.6 \%$ & 74.42 & 39.82 & $46.5 \%$ \\
\hline & $(25.8 \mathrm{I})$ & $(16.08)$ & $P=0.0001$ & $(41.70)$ & $(17.04)$ & $P=0.003$ \\
\hline Nulliparous VAS scores & 92.95 & 45.70 & $50.8 \%$ & 95.78 & 34.90 & $63.6 \%$ \\
\hline$(n=10)$ & (37.09) & $(19.91)$ & $P=0.0011$ & $(60.72)$ & $(17.57)$ & $P=0.0032$ \\
\hline Multiparous VAS scores & 72.39 & 42.98 & $40.6 \%$ & 62.56 & 43.51 & $30.5 \%$ \\
\hline $\operatorname{TCTP}(n=8)$ & $(14.99)$ & $(\mid 3.91)$ & $P=0.0083$ & $(23.22)$ & $(16.81)$ & $P=0.2134$ \\
\hline $\mathrm{BM}(\mathrm{n}=7)$ & & & & & & \\
\hline
\end{tabular}

Abbreviations: TCTP, traditional childbirth training program; BM, Bonapace Method; VAS, visual analog scale.

and improving fetal outcomes (increasing birth weight and reducing prematurity). ${ }^{43}$ The literature on childbirth training programs is inconsistent. ${ }^{12}$ While some studies show no increased outcomes with training, ${ }^{44,45}$ one study showed that women who participated in antenatal classes used less epidural analgesia during labor (relative risk $[\mathrm{RR}]=0.84$, 95\% CI $=0.73-0.97 ; P<0.01)$, but did not experience

\section{A}

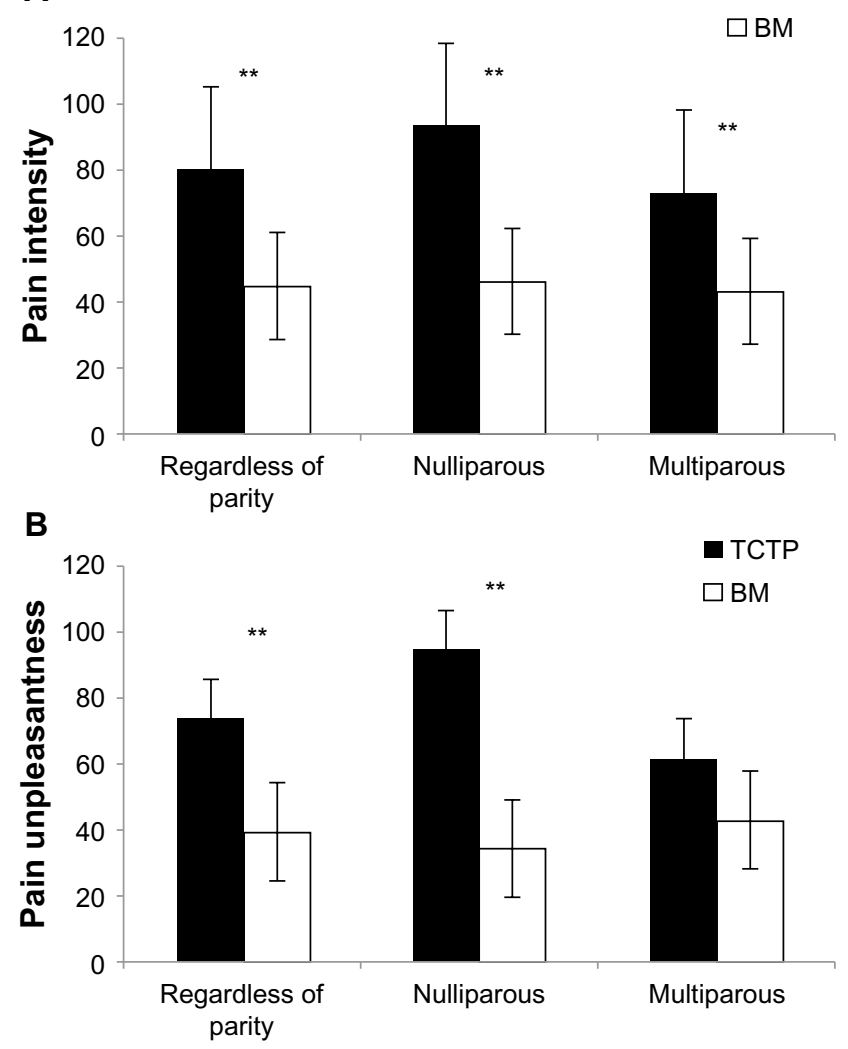

Figure 3 Mean comparison of VAS pain scores.

Notes: Mean comparisons of VAS pain scores show that the BM (white bars) is effective in reducing pain intensity $(\mathbf{A})$ and pain unpleasantness $(\mathbf{B})$, in comparison to TCTP (dark bars), to which it was compared. For pain intensity, the difference is significant for both nulliparous and multiparous women. Mean and SD. $* * P<0.01$. Abbreviations: VAS, visual analog scales; BM, Bonapace Method; TCTP, traditional childbirth training program; SD, standard deviation. less pain relief overall $(\mathrm{RR}=0.99,95 \% \mathrm{CI}=0.94-1.04 ; P$ $<0.72) .{ }^{46}$ Increasing competencies and abilities through practice, feedback, and positive example seems to be an important part of programs that provide positive outcomes. ${ }^{17}$ Our study showed the importance of combining various techniques that influence both components of pain. Consistent with the findings of Price et al, ${ }^{3}$ childbirth - a positive event in the life of a woman - was found to be a more intense than unpleasant experience. This may explain why only the intensity of pain was significantly reduced in multiparous women in our study.

The strengths of this multicenter case control study can be summarized as follows: a sensitive pain measurement tool (scoring range: 0-100) with verbal and numerical descriptors was used, allowing precise and nuanced data to be gathered. Two separate VAS were used, for evaluation of both the sensory and affective components of pain. Numerous assessments of pain perception were made by subjects during all phases of labor and delivery, thus preventing problems related to poor memory of pain and observer bias. Consistent briefing was provided to subjects with regard to the experimental design and the assessment of pain. Subjects were blind with respect to the aim of the study, in order to avoid motivation factors that could impact data (ie, subjects trying to justify the training they followed). Subjects were recruited from five typical regional general hospital maternities in the province of Quebec, which offer the same type of practice and services. When tested for age, finances, parity, and education, groups were found to be comparable (Table 2).

\section{Limitations}

Some confounding factors were not controlled for and may limit the scope of this study. However, it was essential to have data on the efficacy of the BM before ethically conducting a randomized controlled trial in a clinical situation. The data obtained in this study are supportive of a significant reduction 
Table 4 Mean pain perception, standard deviation, and differences in pain reduction between the methods, according to training and different phases of labor and delivery

\begin{tabular}{|c|c|c|c|c|c|c|}
\hline & \multicolumn{3}{|c|}{ Pain intensity } & \multicolumn{3}{|c|}{ Pain unpleasantness } \\
\hline & $\begin{array}{l}\text { TCTP } \\
(n=12)\end{array}$ & $\begin{array}{l}\text { BM } \\
(n=13)\end{array}$ & Difference & $\begin{array}{l}\text { TCTP } \\
(n=12)\end{array}$ & $\begin{array}{l}\text { BM } \\
(n=13)\end{array}$ & Difference \\
\hline \multirow[t]{2}{*}{ Early } & 47.45 & 30.54 & $35.6 \%$ & 36.64 & 26.98 & $26.4 \%$ \\
\hline & $(5.31)$ & $(4.74)$ & $P=0.03$ & $(7.76)$ & $(4.88)$ & $P=0.29$ \\
\hline \multirow[t]{2}{*}{ Active } & 69.11 & 41.00 & $40.7 \%$ & 59.37 & 39.99 & $32.6 \%$ \\
\hline & $(5.75)$ & $(4.4)$ & $P=0.0007$ & $(7.7 I)$ & $(5.43)$ & $P=0.049$ \\
\hline \multirow[t]{2}{*}{ Transition } & 91.96 & 66.29 & $27.9 \%$ & 87.25 & 57.23 & $34.4 \%$ \\
\hline & $(5.77)$ & $(7.14)$ & $P=0.01$ & $(8.78)$ & $(6.17)$ & $P=0.009$ \\
\hline \multirow[t]{2}{*}{ Pushing } & 97.91 & 66.55 & $32.0 \%$ & 101.05 & 53.83 & $46.7 \%$ \\
\hline & $(I I .21)$ & $(6.79)$ & $P=0.023$ & $(11.06)$ & $(9.01)$ & $P=0.003$ \\
\hline
\end{tabular}

Abbreviations: TCTP, traditional childbirth training program; BM, Bonapace Method.

of pain with the BM, and future studies are needed to confirm our results. A problem in evaluating the possible effects of preparation for childbirth is whether motivation is chiefly responsible for benefits conferred by preparation rather than the preparation itself. Because all women in this study sought preparation and were prepared to varying degrees, all women
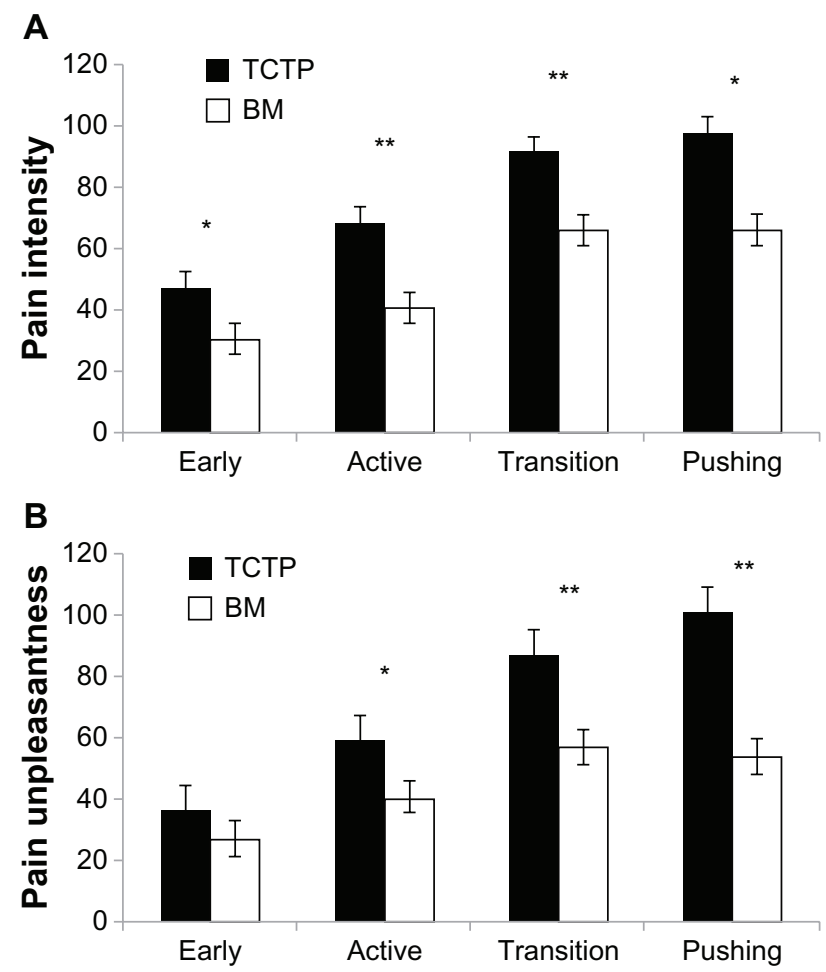

Figure 4 Mean comparison of VAS pain scores.

Notes: Mean comparison of VAS pain scores for all phases of labor and delivery illustrate pain intensity $(\mathbf{A})$ and pain unpleasantness (B) responses at each stage of labor. VAS ratings for the BM group (white bars) were significantly lower during all phases of labor and delivery for pain intensity, in comparison to the TCTP (dark bars). VAS ratings for pain unpleasantness showed a significant reduction during the active, transition and pushing phase (see Table 4). Mean and SD. $* P<0.05$, $* * P<0.01$. Abbreviations: VAS, visual analog scales; BM, Bonapace Method; TCTP, traditional childbirth training program; SD, standard deviation. were motivated to prepare to some extent, which limits the impact of this variable. ${ }^{47}$

The final sample size $(n=25)$ may appear small; it is due to the rigor of the protocol. Many subjects $(n=17)$ were eliminated from the initial sample $(n=42)$ because all data following the use of sedatives or epidural was eliminated, and because subjects needed to record at least two of the four stages of labor and delivery. This loss of subjects had been anticipated considering the popularity of pharmacotherapy. Fortunately, an average of 15 measurements or values were registered per subject, compensating for the size of the sample. As the loss of subjects was identical in both groups, the impact of this variable was limited, as the remaining subjects were evenly distributed in both groups. The number of women eliminated for seeking pharmacological pain relief was identical in both groups $(n=4)$. One may hypothesize that no matter what non-pharmacological method one chooses to use to cope with pain, a certain number of women will still prefer other types of support. Another factor which may have impacted the results of the study is not having accounted for some physical variances that have been known to influence pain, such as the weights of the mother and the child. ${ }^{38}$ Although none of the participating subjects were part of midwifery continuity of care programs, this multicenter case control study, with so few women, could have introduced unaccounted-for variables, such as different models of care in the different hospitals.

Even though subjects were unaware of the purpose of the study, a potential placebo effect related to positive expectations could have occurred within the group that undertook BM training, because participants were told throughout their classes that the purpose of the method was to reduce pain in labor. Discussing pain, and building tools to cope with pain that are conducive to positive 
expectations is part of the Bonapace Method, as with other educational methods.

\section{Recommendations}

Randomized controlled trials should be conducted in order to determine the efficacy of this childbirth-training program, evaluating not only pain perception but also obstetric interventions, maternal, and neonatal outcomes. In order to better understand the impact of the three endogenous pain-modulating mechanisms and the role of each component of pain, a metaanalysis of non-pharmacological studies should pool together sufficient quality data to determine what works best. Based on the results of this study, which includes techniques from all three endogenous mechanisms that modulate both components of pain, it can be hypothesized that training programs should teach expecting parents techniques that modulate both components of pain. The implications of this study are important, considering the rising levels of medical intervention associated with pharmacological pain management techniques. ${ }^{11}$

The use of a structured pain control program based on neurophysiological mechanisms shows an important effect on reducing pain during labor.

\section{Acknowledgments}

We wish to thank the nurses of the Hôpital Hôtel-Dieu d'Amos, Sister Claire Brisebois, and Paule Julien for their valuable collaboration in the collection of data, and Clare Lord for her invaluable revision of the final draft. Serge Marchand is supported by research grants from the Candadian Institute of Health Research and is a supported member of the Centre de Recherche Clinique Étienne le Bel. Julie Bonapace is the author of a book and training material on the Bonapace Method.

\section{Disclosure}

The authors report no conflicts of interest in this work.

\section{References}

1. IASP Task Force on Taxonomy, Classification of Chronic Pain. 2nd ed. Merskey H, Bogduk N, editors. Seattle, WA: IASP Press; 1994.

2. Melzack R, Taenzer P, Feldman P, Kinch RA. Labour Is still painful after prepared childbirth training. Can Med Assoc J. 1981;125:357-363.

3. Price DD, Harkins SW, Baker C. Sensory-affective relationships among different types of clinical and experimental pain. Pain. 1987;28:297-307.

4. Bonica J. Labour pain. In: Wall PD, Melzack R, editors. Textbook of Pain. 3rd ed. New York: Churchill Livingstone; 1994:615-641.

5. Brownridge P. The nature and consequences of childbirth pain. Eur $J$ Obstet Gynecol Reprod Biol. 1995;59:S9-S15.

6. Collis RE, Davies DW, Aveling W. Randomised comparison of combined spinal-epidural and standard epidural analgesia in labour. Lancet. 1994;345(8962):1413-1416.
7. McCool W, Packman J, Zwerling A. Obstetric anesthesia: Changes and choices. J Midwifery Womens Health. 2004;49:505-513.

8. Lieberman E, O'Donoghue C. Unintended effects of epidural analgesia during labor: A systematic review. Am J Obstet Gynecol. 2002;186: S31-S68.

9. Lucas M, Sharma S, McIntire D, et al. A randomized trial of labor analgesia in women with pregnancy-induced hypertension. Am J Obstet Gynecol. 2001;185:S970-S975.

10. Wlody D. Complications of regional anesthesia in obstetrics. Clin Obstet Gynecol. 2003;46:667-678.

11. Anim-Somuah M, Smyth RMD, Jones L. Epidural versus nonepidural or no analgesia in labour. Cochrane Database Syst Rev. 2011;12:CD000331

12. Gagnon AJ, Sandall J. Individual or group antenatal education for childbirth or parenthood, or both. Cochrane Database Syst Rev. 2007;3:CD002869.

13. Davenport-Slack B, Boylan CH. Psychological correlates of childbirth pain. Psychosomatics. 1974;36:215-223.

14. Javert CT, Hardy JD. Measurement of pain intensity in labor and its physiologic, neurobiologic, and pharmacologic implications. Am J Obstet Gynecol. 1950;60:552-563.

15. Bergstöm-Whalen MB. Efficacy of education for childbirth. J Psychosom Res. 1963;7:131-146.

16. Cattani P, Sina P, Piccolboni G, Dell'Angelo M, Zanarotti R. Effect of autogenic respiratory training on labor pain. Use of the Vao $\mathrm{Na}$ Algometers. Minerva Ginecol. 1991;43:525-528.

17. Ip WY, Tang CS, Goggins WB. An educational intervention to improve women's ability to cope with childbirth. J Clin Nurs. 2009;18: 2125-2135.

18. Melzack R. Labour pain as a model of acute pain. Pain. 1993;53: $117-120$.

19. Marchand S, Bushnell MC, Molina-Negro P, Martinez SN, Duncan GH. The effects of dorsal column stimulation on measures of clinical and experimental pain in man. Pain. 1991;45:249-257.

20. Nettelbladt P, Fagerström CF, Uddenberg N. The significance of reported childbirth pain. J Psychosom Res. 1976;20:215-221.

21. Marchand S. The Phenomenon of Pain. Seattle, WA: IASP Press; 2012.

22. Smith CA, Levett KM, Collins CT, Crowther CA. Relaxation techniques for pain management in labour. Cochrane Database Syst Rev. 2011;12:CD009514.

23. Chalaye P, Goffaux P, Lafrenaye S, Marchand S. Respiratory effects on experimental heat pain and cardiac activity. Pain Medicine. 2009;10:1334-1340.

24. Melzack R, Wall PD. Pain mechanisms: a new theory. Science. 1965;150: 971-979.

25. Tsao JC. Effectiveness of massage therapy for chronic, non-malignant pain: a review. Evid Based Complement Alternat Med. 2007;4:165-179.

26. Smith CA, Levett KM, Collins CT, Jones L. Massage, reflexology and other manual methods for pain management in labour. Cochrane Database Syst Rev. 2012;2:CD009290.

27. Jones L, Othman M, Dowswell T, et al. Pain management for women in labour: an overview of systematic reviews. Cochrane Database Syst Rev. 2012;3:CD009234

28. Lawrence A, Lewis L, Hofmeyr GJ, Dowswell T, Styles C. Maternal positions and mobility during first stage labour. Cochrane Database Syst Rev. 2009;2:CD003934.

29. Le Bars D, Dickenson AH, Besson JM. Diffuse noxious inhibitory controls (DNIC). I. Effects on dorsal horn convergent neurones in the rat. Pain. 1979;6:283-304.

30. Le Bars D, Dickenson AH, Besson JM. Diffuse noxious inhibitory controls (DNIC). II. Lack of effect on non-convergent neurones, dupraspinal involvement and theoretical implications. Pain. 1979;6: 305-327.

31. Smith CA, Collins CT, Cyna AM, Crowther CA. Complementary and alternative therapies for pain management in labour. Cochrane Database Syst Rev. 2010;9:CD003521. 
32. Bing Z, Villanueva L, Le Bars D. Acupuncture and diffuse noxious inhibitory controls: naloxone-reversible depression of activities of trigeminal convergent neurons. Neuroscience. 1990;37:809-818.

33. Hashimoto T, Aikawa S. Manual acupuncture and its central mechanisms: involvement of propriospinal and descending pain inhibitory system. J Jpn Soc Acupunct. 1994;44:181-190.

34. Hjelmstedt A, Shenoy ST, Stener-Victorin E, et al. Acupressure to reduce labor pain: a randomized controlled trial. Acta Obstet Gynecol Scandinavica. 2010;89:11:1453-1459.

35. Smith CA, Collins CT, Crowther CA, Levett KM. Acupuncture or acupressure for pain management in labour. Cochrane Database Syst Rev. 2011;7:CD009232.

36. Bonapace J. Accoucher sans stress avec la méthode Bonapace. [Childbirth without stress with the Bonapace Method]. Montréal: Editions de 1'Homme; 2009. French.

37. Cunningham FG. Williams Obstetrics. 19th ed. Norwalk, CT: Appleton Lange; 1993.

38. Melzack R. The myth of painless childbirth (the John J Bonica lecture). Pain. 1984;19:321-337.

39. Friedman EA. Normal labor. In : Friedman EA. Labor, editors. Clinical Evaluation and Management. 2nd ed. New York: Appleton-CenturyCrofts; 1978:1-58.

40. Melzack R, Kinch R, Dobkin P, Lebrun M, Taenzer P. Severity of labor pain: influence of physical as well as psychologic variables. Can Med Assoc J. 1984;130:579-584.
41. Hodnett ED, Gates S, Hofmeyr GJ, Sakala C, Weston J. Continuous support for women during childbirth. Cochrane Database Syst Rev. 2011;2:CD003766.

42. Chuntharapat S, Petpichetchian W, Hatthakit U. Yoga during pregnancy: effects on maternal comfort, labor pain and birth outcomes. Complement Ther Clin Pract. 2008;14:105-115.

43. Narendran S, Nagarathna R, Narendran V, Gunasheela S, Nagendra HR. Efficacy of yoga on pregnancy outcome. J Altern Complement Med. 2005;11(2):237-244.

44. Artieta-Pinedo I, Paz-Pascual C, Grandes G, et al. The benefits of antenatal education for the childbirth process in Spain. Nurs Res. 2010;59:194.

45. Bergström M, Kieler H, Waldenström U. Effects of natural childbirth preparation versus standard antenatal education on epidural rates, experience of childbirth and parental stress in mothers and fathers: a randomised controlled multicentre trial. BJOG. 2009;116:1167-1176.

46. Maimburg RD, Vaeth M, Dürr J, Hvidman L, Olsen J. Randomised trial of structured antenatal training sessions to improve the birth process. BJOG. 2010;117:921-928.

47. Entwistle DR, Doering SG. The First Birth. A Family Turning Point. Baltimore, MA: Johns Hopkins University Press; 1981.
Journal of Pain Research

\section{Publish your work in this journal}

The Journal of Pain Research is an international, peer-reviewed, open access, online journal that welcomes laboratory and clinical findings in the fields of pain research and the prevention and management of pain. Original research, reviews, symposium reports, hypothesis formation and commentaries are all considered for publication.

\section{Dovepress}

The manuscript management system is completely online and includes a very quick and fair peer-review system, which is all easy to use. Visit http://www.dovepress.com/testimonials.php to read real quotes from published authors. 